\title{
Effectiveness of growth hormone therapy in children with Noonan syndrome
}

\author{
Eun Mi Seok, MD', \\ Hong Kyu Park, MD', \\ Jung Gi Rho, MD', \\ Change Dae Kum, MD', \\ Hae Sang Lee, $\mathrm{PhD}^{1}$, \\ Jin Soon Hwang, $\mathrm{PhD}^{1}$
}

${ }^{1}$ Department of Pediatrics, Ajou University Hospital, Ajou University School of Medicine, Suwon, Korea

2Department of Pediatrics, Gyeongsang National University Changwon Hospital, Changwon, Korea
Received: 10 September, 2019 Revised: 21 November, 2019 Accepted: 4 February, 2020

Address for correspondence: Hae Sang Lee, PhD

Department of Pediatrics, Ajou University Hospital, Ajou University School of Medicine, 164 World cupro, Yeongtong-gu, Suwon 16499, Korea

Tel: +82-31-219-4454

Faxl: +82-31-219-5169

E-mail: seaon98@ajou.ac.kr

https://orcid.org/0000-0002-96844042
Purpose: Recombinant human growth hormone $(\mathrm{rhGH})$ has been used to improve growth in children with Noonan syndrome (NS). This study aimed to investigate the efficacy of rhGH therapy in Korean children with NS.

Methods: Seventeen prepubertal children (10 boys, 7 girls) with NS who received rhGH therapy for at least 3 years between 2008 and 2017 were included. To compare the response, age- and sex-matched children with GH deficiency (GHD; $\mathrm{n}=31$ ) were included. Height and growth velocity before and during treatment were analyzed.

Results: The mean age of NS patients was $6.34 \pm 2.32$ years. After treatment, the height standard deviation score (SDS) increased from $-2.93 \pm 0.81$ to $-1.51 \pm 1.00$ in patients with NS and from $-2.45 \pm 0.42$ to $-1.09 \pm 0.47$ in patients with GHD. There were no significant differences in growth velocity or change in height SDS between patients with NS and GHD. Growth velocity in the first year of treatment was higher in patients with PTPN11 mutations than those without PTPN11 mutations, but the change in height SDS was not significantly different between those 2 groups.

Conclusion: rhGH therapy can increase linear growth in prepubertal children with NS. The growth response between patients with NS and patients with GHD was not significantly different. Furthermore, we observed that lower doses of growth hormone have a similar effect on height compared to previous studies in patients with NS. Our study indicates that rhGH treatment is useful for growth promotion.

Keywords: Noonan syndrome, Growth hormone, Efficacy

\section{Introduction}

Noonan syndrome (NS) is a normal karyotype genetic disorder characterized by distinctive facial features, postnatal short stature, and cardiac anomalies. NS is observed in 1 per 1,000 to 2,500 live births, with males and females equally affected. ${ }^{1)}$ It is usually clinically diagnosed, but can be confirmed by genetic testing in recent years. Several mutations in the reninangiotensin system (RAS)-methionine-activated protein kinase transduction pathway are thought to induce NS. ${ }^{2)}$ Although NS is an autosomal dominant disorder, it can also occur sporadically. Mutations in the PTPN11 gene are detected in approximately 50\% of patients with NS, whereas $25 \%$ of patients have mutations in other gene pathways, including SHOC2, CBL, SOS1, SOS2, KRAS, NRAS, BRAF, RAF1, RIT1, RRAS, RASA2, A2ML1, and LZTR1. ${ }^{3)}$

Short stature is a common manifestation of NS. The mean height of patients with NS is reported to be more than 2 standard deviations (SDs) below that of the normal population, with the average adult height being $162.5 \mathrm{~cm}$ in men and $152.7 \mathrm{~cm}$ in women. ${ }^{4)}$ The cause of short stature in NS has not been clearly demonstrated, but genetic mutations limiting the action of growth hormone $(\mathrm{GH})$ seem to be a major factor. ${ }^{5)}$ Consequently, the U.S. Food and Drug Administration approved recombinant human $\mathrm{GH}(\mathrm{rhGH})$ for treatment of short stature in patients with NS in 2007. rhGH therapy has been shown to increase height standard deviation scores (SDS) and accelerate growth velocity in patients with NS, but current data are 
limited. ${ }^{6)}$

In this study, we aimed to compare the effects of rhGH therapy in Korean children with NS to those in children with GH deficiency (GHD).

\section{Materials and methods}

\section{Patients}

We retrospectively reviewed the data of 33 patients who were diagnosed with NS at Ajou University Hospital between March 2008 and May 2017. Among the 33 patients, we enrolled 17 prepubertal patients who received rhGH therapy for at least 3 years. Patients were clinically diagnosed with NS based on van der Burgt scores, ${ }^{7)}$ and prepubertal status was defined as absence of breast development in girls and testicular volume $<4 \mathrm{~mL}$ in boys. All patients underwent mutational analysis of PTPN11 and NS-related genes.

To compare the response to rhGH therapy, patients with GHD who were matched by age and sex were recruited as the control group. A total of 31 GHD patients with height below the third percentile and delayed bone age were enrolled. Patients with GHD had a GH peak $<10 \mathrm{ng} / \mathrm{mL}$ on provocation with a combination of at least 2 stimulants. All patients with GHD received $\mathrm{rhGH}$ at $0.7 \mathrm{IU} / \mathrm{kg}$ (initial mean dose, $32.9 \pm 3.2 \mu \mathrm{g} / \mathrm{kg} /$ day) for 6 days per week.

\section{Study design}

rhGH was administered subcutaneously at a dose of $1 \mathrm{IU} /$ $\mathrm{kg}$ (initial mean dose, $47.3 \pm 9.3 \mu \mathrm{g} / \mathrm{kg} /$ day) for 6 days per week in patients with NS. Patients' height, weight, bone age, insulin-like growth factor-1 (IGF-1) level, pubertal status, and thyroid function were collected from medical records at the time of evaluation and every 6 months. The IGF-1 SDS for age and sex was calculated according to normal IGF-1 levels for age and sex. ${ }^{8)}$ Height was measured using a Harpenden stadiometer (Holtain Ltd., Crymych, UK), whereas body weight was measured with a digital scale. Body mass index (BMI) was calculated using the patient's height and weight. SDS of height, weight, and BMI were calculated according to 2017 Korean National Growth Charts. ${ }^{9)}$ Bone age was assessed by the Greulich-Pyle method. ${ }^{10)}$ Pubertal status was assessed using the Tanner and Marshall method based on genital development in boys and breast development in girls. ${ }^{11)}$

\section{Laboratory measurements}

Of the 17 NS patients, 7 underwent GH stimulation tests. Dopamine (Sinemet; 10-mg carbidopa/100-mg levodopa; $\left.150-175 \mathrm{mg} / \mathrm{m}^{2}\right)$ or insulin $(0.05 \mathrm{IU} / \mathrm{kg})$ was administered at time 0 . Blood was collected before testing ( 0 minutes) to obtain the baseline level and at 30-minute intervals for 2 hours after administration of the test. Serum GH (BioSource, Nivelles,
Belgium) and IGF-1 (Biocode, Hycel, Liége, Belgium) levels were measured using immunoradiometric assays.

\section{Statistical analysis}

Results are reported as mean \pm SD unless otherwise noted. To assess differences between groups, an independent $t$-test was used. To evaluate changes in height SDS and growth velocity before and after rhGH therapy, a paired $t$-test was used. Statistical analysis was performed using IBM SPSS Statistics ver. 23.0 (IBM Co., Armonk, NY, USA), with $P<0.05$ considered statistically significant.

\section{Results}

\section{Subject characteristics}

The baseline characteristics of patients with NS and GHD are shown in Table 1 . The mean age at initial diagnosis in patients with NS was $6.34 \pm 2.32$ years. Cardiac defects were observed in 13 patients $(76.4 \%)$, including atrial septal defects ( 5 patients, $38.4 \%$ ), pulmonary stenosis (5 patients, $38.4 \%$ ), ventricular septal defects (2 patients, 15.3\%), patent ductus arteriosus (2 patients, $15.3 \%$ ), hypertrophic subaortic stenosis (2 patients, $15.3 \%)$, and mitral regurgitation with mitral valve prolapse (1 patient, 7.6\%). All patients with NS and GHD were prepubertal when they started rhGH therapy. Of the 7 NS patients who underwent GH stimulation tests, 3 (42.8\%) showed GHD (GH peak $<10 \mathrm{ng} / \mathrm{mL}$ ).

\section{Response to rhGH therapy in patients with NS and GHD}

There were no significant differences in age or height SDS between the 2 groups, but the rhGH dose was significantly higher in patients with NS than in those with GHD (Table 1).

Table 1. Baseline characteristics and comparison of the rhGH responses in patients with NS and GHD

\begin{tabular}{|c|c|c|c|}
\hline Variable & NS $(n=17)$ & $\mathrm{GHD}(\mathrm{n}=31)$ & $P$-value \\
\hline Age (yr) & $6.34 \pm 2.32$ & $6.35 \pm 1.84$ & 0.996 \\
\hline Sex, male:female & $10: 7$ & $22: 9$ & $0.524^{*}$ \\
\hline Height SDS & $-2.93 \pm 0.81$ & $-2.45 \pm 0.42$ & 0.037 \\
\hline Weight SDS & $-2.22 \pm 1.18$ & $-1.85 \pm 0.92$ & 0.242 \\
\hline BMI SDS & $-0.40 \pm 1.10$ & $-0.36 \pm 1.10$ & 0.902 \\
\hline IGF-1 SDS & $-0.27 \pm 1.09$ & $-0.56 \pm 1.06$ & 0.371 \\
\hline Bone age (yr) & $5.22 \pm 1.93$ & $4.77 \pm 1.60$ & 0.416 \\
\hline $\mathrm{BA}-\mathrm{CA}$ & $-1.35 \pm 0.95$ & $-1.57 \pm 0.64$ & 0.417 \\
\hline Initial mean GH dose ( $\mu \mathrm{g} / \mathrm{kg} /$ day) & $47.3 \pm 9.3$ & $32.9 \pm 3.2$ & $<0.001$ \\
\hline
\end{tabular}

Values are represented as mean \pm standard deviation or number. $\mathrm{GH}$, growth hormone; rhGH, recombinant human GH; NS, Noonan syndrome; GHD, GH deficiency; SDS, standard deviation score; $\mathrm{BMI}$, body mass index; $\mathrm{BA}-\mathrm{CA}$, difference between bone age and chronological age.

"The proportion of sex was compared using the chi-square test. 


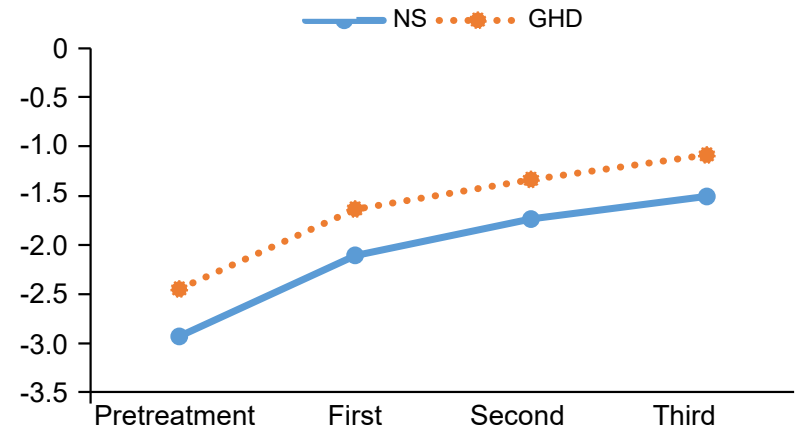

(A) Height SDS

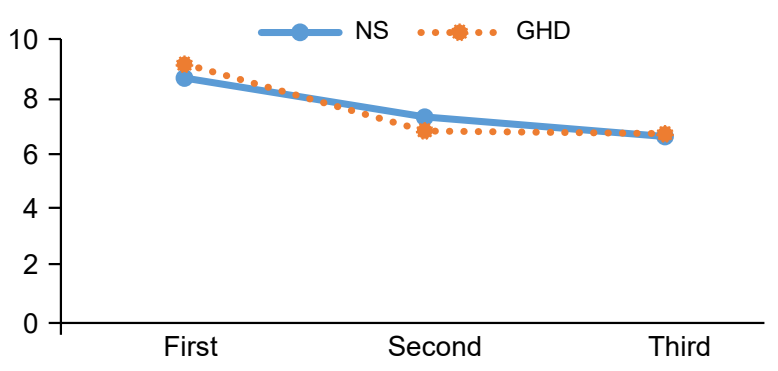

(B) Growth velocity

Fig. 1. Change in height SDS (A) and growth velocity (B) before and after rhGH therapy in children with NS and GHD. SDS, standard deviation score; rhGH, recombinant human growth hormone; NS, Noonan syndrome; GHD, growth hormone deficiency.

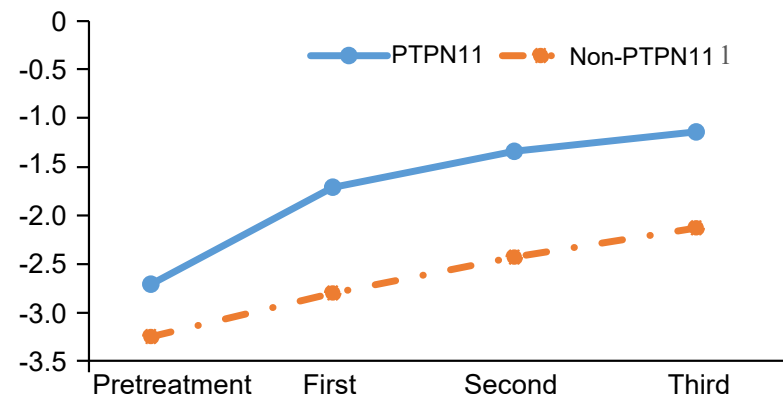

(A) Height SDS

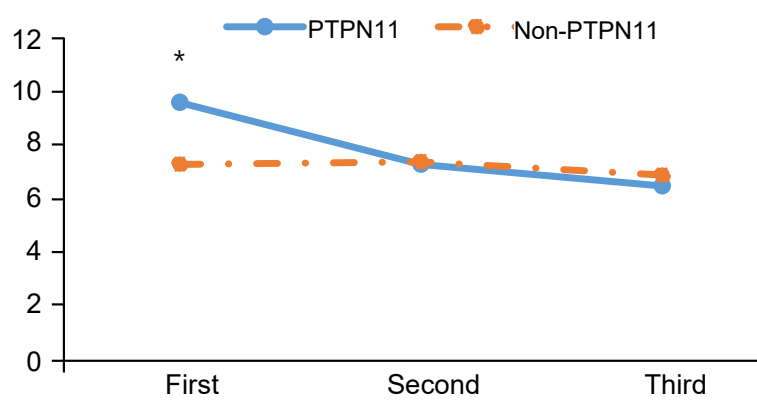

(B) Growth velocity

Fig. 2. Change in height SDS (A) and growth velocity (B) before and after rhGH therapy in the PTPN11 and non-PTPN11 groups. ${ }^{*} P<0.05$, compared to the growth velocity of the non-PTPN11 group. SDS, standard deviation score; rhGH, recombinant human growth hormone; non-PTPN11, patients for which PTPN11 mutations were not found.

The height SDS in patients with NS was $-2.11 \pm 1.00$ after 1 year of treatment, $-1.74 \pm 1.06$ after 2 years of treatment, and $-1.51 \pm 1.00$ after 3 years of treatment (Fig. 1). The growth velocity in patients with NS was highest during the first year of treatment $(8.8 \pm 1.9 \mathrm{~cm})$, which decreased to $7.4 \pm 1.1 \mathrm{~cm}$ in the second year and to $6.7 \pm 1.1 \mathrm{~cm}$ in the third year. After 3 years of rhGH therapy, the height SDS in patients with NS increased from $-2.93 \pm 0.81$ to $-1.51 \pm 1.00(P<0.05)$.

The height SDS in patients with GHD significantly increased from $-2.45 \pm 0.42$ to $-1.64 \pm 0.47$, to $-1.34 \pm 0.45$, and to $-1.09 \pm 0.47$ at the first, second, and third years of treatment, respectively (Fig. 1). The growth velocity in patients with GHD was also highest during the first year of treatment $(9.3 \pm 1.7 \mathrm{~cm})$ and decreased to $6.9 \pm 1.2 \mathrm{~cm}$ in the second year and to $6.8 \pm 1.8 \mathrm{~cm}$ in the third year. The growth velocities and changes in height SDS over 3 years were not significantly different between patients with NS and those with GHD $(P=0.800)$.

During rhGH therapy, no patients in either group showed significant adverse effects such as glucose intolerance, tumor development, or thyroid dysfunction.

\section{Response to rhGH therapy based on PTPN11 mutation}

In the patients with NS, mutations in PTPN11, RAF1, and SHOC2 genes were identified in 11 (64.7\%), $1(5.8 \%)$, and 1 patient (5.8\%), respectively; 4 patients $(23.5 \%)$ had no mutations in any NS-related genes. Four patients were diagnosed with typical facial dysmorphology and less than one-third percentile height, and they each had a cardiac defect: pulmonary stenosis (1 patient), mitral regurgitation with mitral valve prolapse (1 patient), patent ductus arteriosus (1 patient), and hypertrophic subaortic stenosis (1 patient). There were no significant differences in clinical or laboratory findings between patients with and without PTPN11 mutations at the start of rhGH therapy (Table 2). Growth velocity in the first year of treatment was greater in patients with PTPN11 mutations $(9.6 \pm 2.8 \mathrm{~cm})$ than in those without PTPN11 mutations $(7.3 \pm 2.0 \mathrm{~cm})$, but the change in height SDS from baseline to the third year of treatment was $1.25 \pm 0.82$ in patients without PTPN11 mutations and $1.53 \pm 0.46$ in patients with PTPN11 mutations (Fig. 2), which was not significantly different $(P=0.400)$. 
Table 2. Baseline characteristics according to the mutation type for patients with NS

\begin{tabular}{|c|c|c|c|}
\hline Variable & $\begin{array}{l}\text { PTPN11 } \\
(\mathrm{n}=11)\end{array}$ & $\begin{array}{c}\text { Non-PTPN11 } \\
(n=6)\end{array}$ & $P$-value \\
\hline Age (yr) & $5.96 \pm 2.02$ & $7.07 \pm 2.86$ & 0.362 \\
\hline Sex, male:female & $7: 4$ & 3: 3 & $0.643^{\dagger}$ \\
\hline Height SDS & $-2.73 \pm 0.60$ & $-3.27 \pm 1.07$ & 0.201 \\
\hline Weight SDS & $-1.89 \pm 1.39$ & $-2.54 \pm 0.50$ & 0.431 \\
\hline BMI SDS & $-0.27 \pm 1.35$ & $-0.64 \pm 0.37$ & 0.523 \\
\hline IGF-1 SDS & $0.04 \pm 0.75$ & $-0.83 \pm 1.45$ & 0.211 \\
\hline Bone age (yr) & $4.86 \pm 1.80$ & $6.18 \pm 2.19$ & 0.254 \\
\hline $\mathrm{BA}-\mathrm{CA}$ & $-1.09 \pm 0.77$ & $-2.06 \pm 1.15$ & 0.080 \\
\hline $\begin{array}{l}\text { Initial mean GH dose } \\
(\mu \mathrm{g} / \mathrm{kg} / \text { day })\end{array}$ & $50.3 \pm 7.8$ & $41.7 \pm 9.9$ & 0.067 \\
\hline
\end{tabular}

Values are represented as mean \pm standard deviation

NS, Noonan syndrome; SDS, standard deviation score; BMI, body mass index; IGF-1, insulin-like growth factor-1; BA-CA, difference between bone age and chronological age; GH, growth hormone; non-PTPN11, patients for which PTPN11 mutations were not found.

"The non-PTPN11 group included patients for which PTPN11 mutations was not found. ${ }^{\dagger}$ The proportion of sex was compared using chi-square test.

\section{Discussion}

In this study, rhGH therapy in patients with NS increased height SDS during the follow-up period. The response to rhGH therapy was not significantly different between patients with NS and GHD, but the rhGH dose was higher in patients with NS. Moreover, there was no difference in the efficacy of rhGH therapy between NS patients with and without PTPN11 mutations.

Numerous studies have reported increased height SDS and growth velocity with rhGH therapy. ${ }^{12-16)}$ Osio et al. ${ }^{17)}$ reported improved final height outcomes in patients with NS, including a change in height SDS of 1.7 and mean height gain of $13 \mathrm{~cm}$ in boys and $9.8 \mathrm{~cm}$ in girls after 7.5 years of treatment. A study by de Schepper et al. ${ }^{18)}$ also demonstrated an increased height SDS of 0.34 after 1 year of rhGH therapy. Recently, Giacomozzi et al. ${ }^{19)}$ systematically reviewed 5 studies on final or near-final adult height in patients with NS and reported that the change in height SDS was $1.4 \pm 0.8$, corresponding to $9.5 \pm 6.4 \mathrm{~cm}$, after at least 3 years of rhGH therapy. According to KIGS (Pfizer International Growth Database) data, the change in height SDS was 1.2 in boys and 1.0 in girls among 140 patients with NS who had reached near-final height. Although most studies of rhGH therapy in NS were retrospective and included only a small number of patients, rhGH for treatment of growth failure in patients with NS has been shown to be very effective in terms of growth velocity and height outcomes.

Various factors have been reported to affect height gain or final adult height in patients with NS. Age at initiation of rhGH therapy, duration of treatment, genotype, and rhGH dose have been shown to be associated with growth outcome. ${ }^{4,19,20)}$ Some studies have reported that patients with PTPN11 mutations present with more severe short stature and therefore achieve lower adult heights. These results may be related to GH insensitivity or alteration of the growth plate. ${ }^{2,7,21)}$ Jeong et al. ${ }^{13)}$ reported that the height SDS in patients without PTPN11 mutations was significantly greater than that in patients with PTPN11 mutations after 3 years of rhGH therapy. However, Jo et al. ${ }^{12)}$ reported that the growth velocity in patients with PTPN11 mutations was greater than that in patients without mutations in NS-related genes. Malaquias et al. ${ }^{22)}$ reported that patients without $P T P N 11$ mutations showed a poor response to rhGH therapy compared to patients with PTPN11 mutations. Other studies have reported that the response to rhGH therapy was not significantly different according to genotype. ${ }^{15,22,23)} \mathrm{A}$ prospective study of children with NS reported that there were no significant differences in height SDS or growth velocity between patients with and without PTPN11 mutations. ${ }^{15)}$ These studies were conducted with a very small number of patients and short treatment duration. Thus, further evaluation in a larger prospective study with a longer duration is required to determine the effects of rhGH therapy according to genotype.

Lee et al. ${ }^{24)}$ reported that when rhGH was given at $0.81 \pm 0.13$ $\mathrm{U} / \mathrm{kg} / \mathrm{wk}$ to a group of patients with NS group and $0.78 \pm 0.17$ $\mathrm{U} / \mathrm{kg} / \mathrm{wk}$ to a group of patients with GHD, changes in height SDS and growth velocity in patients with NS were lower than those observed in patients with GHD. Ozono et al. ${ }^{25)}$ examined the efficacy of rhGH therapy with 2 different doses $(33 \mu \mathrm{g} / \mathrm{kg} /$ day vs. $66 \mu \mathrm{g} / \mathrm{kg} /$ day) in patients with NS and reported that the effect was greater with the higher dose. In our study, rhGH was administered in $47.3 \mu \mathrm{g} / \mathrm{kg} /$ day doses (initial mean dose) in NS and in $32.9 \mu \mathrm{g} / \mathrm{kg} /$ day doses (initial mean dose) in GHD. The response to rhGH therapy was not significantly different between patients with NS and GHD, although the dose of rhGH in the NS group was higher than that in the GHD group. Thus, in patients with NS, higher doses of rhGH may be needed to achieve the same growth outcome as seen in patients with GHD. However, this demonstrates that even rhGH doses lower than $66 \mu \mathrm{g} / \mathrm{kg} /$ day have beneficial growth outcomes.

Our study has a few limitations. The main limitation is the retrospective study design. In addition, the patient population is small and the duration of rhGH therapy is relatively short.

In conclusion, rhGH therapy in prepubertal patients with NS increased height SDS and growth velocity after 3 years of treatment. Furthermore, the response to rhGH therapy was similar between patients with NS and those with GHD. Our study provides evidence that rhGH therapy is helpful in improving growth in these patients and that a lower dose of rhGH than what was previously shown may be effective during the first 3 years of treatment.

\section{Ethical statement}

The study was approved by the Institutional Review Board (IRB) of Ajou University Hospital (AJIRB-MED-MDB-19-325), and the IRB waived the requirement for written informed 
consent due to the retrospective study design.

\section{Conflict of interest}

No potential conflict of interest relevant to this article was reported.

\section{References}

1. Roberts AE, Allanson JE, Tartaglia M, Gelb BD. Noonan syndrome. Lancet 2013;381:333-42.

2. Binder G. Noonan syndrome, the Ras-MAPK signalling pathway and short stature. Horm Res 2009;71 Suppl 2:6470 .

3. Noordam K. Expanding the genetic spectrum of Noonan syndrome. Horm Res 2007;68 Suppl 5:24-7.

4. Romano AA, Allanson JE, Dahlgren J, Gelb BD, Hall B, Pierpont ME, et al. Noonan syndrome: clinical features, diagnosis, and management guidelines. Pediatrics 2010;126:746-59.

5. Padidela R, Camacho-Hubner C, Attie KM, Savage MO. Abnormal growth in noonan syndrome: genetic and endocrine features and optimal treatment. Horm Res 2008;70:129-36.

6. Yart A, Edouard T. Noonan syndrome: an update on growth and development. Curr Opin Endocrinol Diabetes Obes 2018;25:67-73.

7. van der Burgt I. Noonan syndrome. Orphanet J Rare Dis 2007;2:4.

8. Hyun SE, Lee BC, Suh BK, Chung SC, Ko CW, Kim HS, et al. Reference values for serum levels of insulin-like growth factor-I and insulin-like growth factor binding protein-3 in Korean children and adolescents. Clin Biochem 2012;45:16-21.

9. Kim JH, Yun S, Hwang SS, Shim JO, Chae HW, Lee YJ, et al. The 2017 Korean National Growth Charts for children and adolescents: development, improvement, and prospects. Korean J Pediatr 2018;61:135-49.

10. Greulich WW, Pyle SI. Radiologic atlas of skeletal development of the hand and wrist. 2nd ed. Standford: Stanford University Press, 1959:53.

11. Wheeler MD. Physical changes of puberty. Endocrinol Metab Clin North Am 1991;20:1-14.

12. Jo KJ, Kim YM, Yoon JY, Lee YJ, Han YM, Yoo HW, et al. Comparison of effectiveness of growth hormone therapy according to disease-causing genes in children with Noonan syndrome. Korean J Pediatr 2019;62:274-80.

13. Jeong I, Kang E, Cho JH, Kim GH, Lee BH, Choi JH, et al. Long-term efficacy of recombinant human growth hormone therapy in short-statured patients with Noonan syndrome. Ann Pediatr Endocrinol Metab 2016;21:26-30.
14. Zavras N, Meazza C, Pilotta A, Gertosio C, Pagani S, Tinelli $\mathrm{C}$, et al. Five-year response to growth hormone in children with Noonan syndrome and growth hormone deficiency. Ital J Pediatr 2015;41:71.

15. Choi JH, Lee BH, Jung CW, Kim YM, Jin HY, Kim JM, et al. Response to growth hormone therapy in children with Noonan syndrome: correlation with or without PTPN11 gene mutation. Horm Res Paediatr 2012;77:388-93.

16. Romano AA, Dana K, Bakker B, Davis DA, Hunold JJ, Jacobs J, et al. Growth response, near-adult height, and patterns of growth and puberty in patients with noonan syndrome treated with growth hormone. J Clin Endocrinol Metab 2009;94:2338-44.

17. Osio D, Dahlgren J, Wikland KA, Westphal O. Improved final height with long-term growth hormone treatment in Noonan syndrome. Acta Paediatr 2005;94:1232-7.

18. De Schepper J, Otten BJ, Francois I, Bourguignon JP, Craen $\mathrm{M}$, Van der Burgt I, et al. Growth hormone therapy in prepubertal children with Noonan syndrome: first year growth response and comparison with Turner syndrome. Acta Paediatr 1997;86:943-6.

19. Giacomozzi C, Deodati A, Shaikh MG, Ahmed SF, Cianfarani S. The impact of growth hormone therapy on adult height in noonan syndrome: a systematic review. Horm Res Paediatr 2015;83:167-76.

20. Noonan JA, Kappelgaard AM. The efficacy and safety of growth hormone therapy in children with noonan syndrome: a review of the evidence. Horm Res Paediatr 2015;83:157-66.

21. Binder G, Neuer K, Ranke MB, Wittekindt NE. PTPN11 mutations are associated with mild growth hormone resistance in individuals with Noonan syndrome. J Clin Endocrinol Metab 2005;90:5377-81.

22. Malaquias AC, Noronha RM, Souza TTO, Homma TK, Funari MFA, Yamamoto GL, et al. Impact of growth hormone therapy on adult height in patients with PTPN11 mutations related to Noonan syndrome. Horm Res Paediatr 2019;91:252-61.

23. Noordam C, Peer PG, Francois I, De Schepper J, van den Burgt I, Otten BJ. Long-term GH treatment improves adult height in children with Noonan syndrome with and without mutations in protein tyrosine phosphatase, nonreceptor-type 11. Eur J Endocrinol 2008;159:203-8.

24. Lee S, Kwon AR, Chae HW, Kim HS. Efficacy of growth hormone treatment in patients with Noonan syndrome and growth hormone deficiency. J Korean Soc Pediatr Endocrinol 2011;16:100-5.

25. Ozono K, Ogata T, Horikawa R, Matsubara Y, Ogawa Y, Nishijima K, et al. Efficacy and safety of two doses of Norditropin((R)) (somatropin) in short stature due to Noonan syndrome: a 2-year randomized, double-blind, multicenter trial in Japanese patients. Endocr J 2018;65:15974. 